\title{
A Compreensão da Experiência de Depressividade na Tradição da Psicopatologia Fenomenológica
}

\author{
Camila Souza $^{1, *} \&$ Virginia Moreira ${ }^{1}$ \\ ${ }^{1}$ Universidade de Fortaleza, Fortaleza, CE, Brasil
}

\begin{abstract}
RESUMO - Estudos sobre a depressão e a melancolia ocuparam um lugar de importância na tradição da psicopatologia fenomenológica. O desenvolvimento desses estudos esbarrou na descrição da experiência de depressividade como o fundamento constitutivo para a compreensão da própria depressão. Arthur Tatossian foi o teórico que, ao estudar o vivido depressivo, resgatou a experiência de depressividade e a sua importância jaz na saída de um pensamento voltado aos conteúdos materiais do vivido depressivo para a experiência vivida que engloba tal fenômeno. Neste artigo, temos como objetivo compreender a experiência de depressividade, com base no pensamento de Tatossian, e as contribuições da tradição da psicopatologia fenomenológica para o desenvolvimento dessa experiência.
\end{abstract}

PALAVRAS-CHAVE: depressão, depressividade, Arthur Tatossian, psicopatologia fenomenológica

\section{Understanding the Experience of Depressivity from the Tradition of Phenomenological Psychopathology}

\begin{abstract}
Studies on depression and melancholy occupied an important place in the tradition of phenomenological psychopathology. The development of these studies stalled in describing the experience of depressivity as the constitutive basis for understanding depression itself. Arthur Tatossian was the theorist who, while studying the experienced depression, rescued the experience of depressivity and its importance lies in the output of a thought directed to the material contents of the experienced depression for the experience that encompasses such a phenomenon. In this this article, we aim to understand the experience of depressivity, based on Tatossian's work, and the contributions of phenomenological psychopathology's tradition to develop this experience.

KEYWORDS: depression, depressivity, Arthur Tatossian, phenomenological psychopathology
\end{abstract}

Ao longo de toda a tradição da psicopatologia fenomenológica, a temática da depressão e da melancolia - seu modo de aparecimento mais grave - é discutido e debatido por diversos autores, estando inclusive relacionada com o próprio desenvolvimento histórico dessa perspectiva. Já a depressividade aparece mais especificamente com o pensamento de Arthur Tatossian, configurando-se como a base constitutiva da depressão (Tatossian, 1979/2006, 1980).

Vale ressaltar, entretanto, que esse termo não é de uso exclusivo de Tatossian, embora o seja desde uma compreensão eminentemente fenomenológica. Encontramos referências sobre a depressividade em alguns escritos de Pierre Fédida (2009), na perspectiva da psicopatologia fundamental que, malgrado dialogar com a psicopatologia fenomenológica, diferencia-se dela. Fédida, em seus estudos sobre a depressão, aponta a necessidade de se compreender a depressividade como uma forma de manutenção da vida psíquica do sujeito. De uma perspectiva da psicopatologia fundamental, Fédida acentua que "a depressividade não é de forma alguma o estado deprimido. É, antes, essa reapropriação do psíquico com suas próprias temporalidades" (p. 37). Ele não a classifica como forma de depressão, mas a relaciona com o equilíbrio da vida psíquica. Segundo Fédida, a depressividade possui um traço de positividade, sendo necessária à vida psíquica como forma de criatividade e o estado deprimido seria justamente a queda dessa "capacidade depressiva". Como ressalta Fédida, a psicoterapia analítica atua nesse ponto específico, restituindo ao sujeito sua criatividade psíquica.

\footnotetext{
*E-mail: camila_psouza@hotmail.com
} 
$\mathrm{Na}$ psicopatologia fenomenológica, o termo depressividade é abordado sobre uma lente diferenciada daquela da psicopatologia fundamental. Aparece no decorrer da obra de Arthur Tatossian (1975, 1977, 1979/2006, 1980) estando atrelado com a sua forma de compreensão do vivido depressivo, que se dá sempre na relação do sujeito com a sua experiência, fazendo-se necessário compreender o seu significado e a sua importância no pensamento de Tatossian.

No entanto, para a compreensão da experiência de depressividade descrita por Tatossian $(1975,1979 / 2006$, 1980), carecemos de um retorno aos fundamentos da própria psicopatologia fenomenológica e de seu desenvolvimento histórico no que se refere à compreensão do vivido depressivo. Esse é um dado relevante, pois a elaboração do pensamento de Tatossian, especialmente no que se refere à depressividade, parte do desenvolvimento ou da crítica de ideias elaboradas anteriormente por autores representantes dessa área (Moreira, 2011, 2012).

Este artigo tem como objetivo compreender a experiência de depressividade com base no pensamento de Arthur Tatossian (1975, 1977, 1979/2006, 1980) e, para alcançá-lo, propomos-nos a discutir o desenvolvimento dessa experiência no percurso da tradição da psicopatologia fenomenológica, no que se refere à depressão, representada pela proposta dos autores Minkowski (1933/1995), Binswanger (1960/2005) e Tellenbach (1961/1976, 1969/1999, 1976). Dado esse que não desmerece a contribuição dos demais autores da área, mas nos auxiliará na escolha do caminho traçado para elaborar este artigo, uma vez que identificamos um diálogo mais intenso entre Tatossian e os autores aqui escolhidos para compreender a depressividade.

\section{A DEPRESSIVIDADE NA TRADIÇÃO DA PSICOPATOLOGIA FENOMENOLÓGICA}

Minkowski (1933/1995), Binswanger (1960/2005) e Tellenbach $(1961 / 1976,1969 / 1999,1976)$ foram alguns dos primeiros psiquiatras que, no campo da Fenomenologia, desenvolveram propostas de se pensar uma prática clínica, especificamente a respeito do transtorno melancólico, pautada na descrição e na compreensão dos vividos psicopatológicos como um modo existencial, distanciando-se de um modelo psiquiátrico clássico ou de uma psicopatologia geral que se voltava para a classificação e diagnóstico das doenças mentais. Apesar da amplitude de publicações expressa por parte de cada um desses autores, deteremo-nos naquelas que priorizam a reflexão e a discussão do vivido depressivo e quais as suas contribuições para pensamos a depressividade, termo desenvolvido posteriormente por Tatossian (1975, 1977, 1979/2006, 1980).

A ideia que circunda a depressividade corresponde a um movimento continuo e oriundo da experiência vivida do paciente. Essa imagem é reconhecida no campo da psicopatologia fenomenológica desde o seu princípio nos anos 1920. Contudo, essa era uma época que não possuía os fundamentos conceituais adequados para uma abordagem histórica do homem, como ressalta Tatossian $(1975,1979 / 2006)$. A ideia de um movimento que comporta a experiência do viver humano, também presente no movimento da depressividade enquanto fenômeno, manifesta-se nos estudos de Minkowski (1933/1995) e a sua contribuição para pensá-la posteriormente por Tatossian se dá no sentido de uma elaboração das descrições dos mundos já constituídos no vivido depressivo.

Eugene Minkowski teve como principal contribuição para a psicopatologia fenomenológica a tessitura de uma obra que auxilia a compreender os transtornos psicopatológicos através da relação do sujeito com sua vivência do tempo. Para ele, a temporalidade era o eixo primordial para a compreensão das psicopatologias e, dessa forma, inaugurou a concepção de tempo vivido para abordar os transtornos depressivos (Abreu \& Silva, 2004; Costa \& Medeiros, 2009). Por meio do trabalho desenvolvido por Minkowski (1933/1995), entendemos que, por ele encontrar-se em uma vertente inicial da psicopatologia fenomenológica, o seu alcance da gênese constitutiva do adoecer mental se deu de forma embrionária, mantendo-se mais próximo de uma fenomenologia descritiva e de sua experiência clínica.

É necessário retomarmos este aspecto, pois constitui um traço significativo para entendermos a contribuição de Minkowski (1933/1995) no que tange à ideia de depressividade. Por encontrar-se na base constitutiva da depressão, a depressividade engloba toda a estrutura existencial do sujeito bem como as condições de possibilidade para a sua emergência enquanto fenômeno (Tatossian, 1980). Ao se manter em um momento descritivo da fenomenologia, diante daquilo que já está constituído como fenômeno da depressão - a saber, o tempo -, Minkowski não se debruça sobre os aspectos que compõem os dados constituintes da existência. Distancia-se, assim, da gênese fenomenológica do vivido depressivo e, com ele, dos fenômenos constituintes da depressividade.

Constatamos, entretanto, que Minkowski (1933/1995) se aproxima da ideia de depressividade quando ressalta a necessidade de priorizar a experiência do paciente e de seu vivido, que se dá na clínica. Tatossian (1979/2006) resgata essa perspectiva estabelecida por Minkowski para pensar a experiência do paciente como eixo central no que tange à depressividade e dialoga com as descrições estabelecidas do mundo vivido já constituído na depressão, abrindo caminhos para melhor compreendê-la.

Diferentemente de Minkowski, Ludwig Binswanger (1960/2005) consegue estabelecer uma fenomenologia egológica ou genética, que buscava a origem dos transtornos psicopatológicos, possibilitando alcançar a gênese da 
depressão e sua base constitutiva. Com Binswanger e sua aproximação à filosofia heideggeriana, surgem os subsídios necessários para uma compreensão da constituição da depressão e, assim, a possibilidade para pensarmos a depressividade.

É um novo caminho, em que é lícito ir além de um entendimento puramente psicológico ou biográfico do adoecer melancólico. Esse percurso é ressaltado por Tatossian (1979/2006) como necessário para a compreensão da globalidade do vivido depressivo, alcançando a gênese subjetiva da depressão. Sem a passagem a uma fenomenologia egológica, pensar acerca da depressividade seria impossível, pois esta está na base constitutiva que origina a própria depressão. Ao abordar a passagem de uma fenomenológica descritiva à genética, Binswanger (1960/2005) resolve o problema da gênese constitutiva do transtorno melancólico e abre caminhos para posteriores discussões acerca da depressividade.

Contudo, ao propor uma compreensão da gênese melancólica por um viés unicamente transcendental, Binswanger (1960/2005) abre margens para uma série de discussões no campo da clínica e da psiquiatria, que criticam o acentuado caráter a-histórico atribuído à melancolia, desconsiderando outras questões como as alterações corporais que se apresentam no doente. Tatossian (1979/2006) acentua que o problema da gênese biográfica das psicoses deve ser posto para a fenomenologia, como evidenciado nos escritos de Binswanger, porém, é necessário priorizar a experiência do sujeito.

Binswanger (1960/2005) não alcança a experiência da depressividade por deixar o vivido do paciente em segundo plano, em decorrência de uma excessiva exposição e análises teóricas e metodológicas. A depressividade não está apenas na gênese das alterações subjetivas do sujeito, também comporta dados da experiência imediata que se faz sobre os conteúdos já constituídos do vivido. É com as publicações de Tellenbach $(1961 / 1976,1969 / 1999,1976)$ que ocorre uma aproximação nesse sentido, dando um alcance clínico mais geral para a compreensão das psicoses e orientando a exposição do problema melancólico.

Superar o pensamento dualista, apontando para uma compreensão ambígua em fenomenologia dos transtornos psicopatológicos é o aporte necessário para a compreensão da depressividade e de seu movimento. Esse caminho só é alcançado em sua plenitude através do pensamento de Tatossian $(1975,1977,1979 / 2006,1980)$, ainda que, com a obra de Tellenbach $(1961 / 1976,1969 / 1999,1976)$, possamos vislumbrar seus delineamentos.

Dos autores aqui introduzidos, Tellenbach (1961/1976, 1969/1999, 1976) é quem mais se aproxima da ideia de depressividade discutida por Tatossian ao desenvolver estudos sobre as depressões endógenas, as quais encontrarse-iam em um terceiro campo etiológico que não se refere apenas aos dados do soma ou da psique, mas se insere na interseção de ambos. Pensar as questões do endon, como Tellenbach (1976, 1969/1999) o fez, é se aproximar em alguns momentos de um posicionamento ambíguo, encontrado e radicalizado por Tatossian (1979/2006) como fio condutor de sua obra.

A importância de pensar o endógeno reside justamente no movimento dialético que se manifesta na inter-relação do endon com a existência. Ressalta-se que o psicopatológico não se resume àquilo herdado como traço somático e biológico, ou apenas psicológico, mas também não negando o papel desses aspectos.

Os estudos de Tellenbach (1969/1999) no terreno da psicopatologia fenomenológica concernem prioritariamente às psicoses endógenas e, entre elas, há um destaque para a depressão. A sua forma de abordar o transtorno depressivo nos remete à ideia desenvolvida posteriormente por Tatossian (1979/2006) acerca da depressividade, pois esta, assim como o endon, possui traços de um movimento constitutivo e sempre em fluxo da experiência do sujeito. É da ordem do fenômeno e não pode ser inferida como uma noção teórica atingida conceitualmente.

A noção de typus melancholicus desenvolvida por Tellenbach é um bom exemplo de um pensamento fenomenológico ambíguo. Por meio de atendimentos a 110 pacientes depressivos, Tellenbach se propôs a compreender o movimento da experiência e dos modos de ser desses pacientes, encontrando, assim, um tipo ou uma "pré-disposição" à depressão, mas sem esgotá-la em si mesma, pois não descarta os dados singulares da experiência imediata (Ambrosini, Stanghellini, \& Langer, 2011). Deparamos-nos, então, com uma forte aproximação com a ideia de depressividade, pois, assim como ela, o endon também é compreendido como gênese, possui traços de um movimento constitutivo próprios do viver humano.

No livro Melancholia, publicado originalmente em 1961, Tellenbach utiliza o termo depressividade ao discorrer sobre a nosologia e a sistemática das melancolias. Para ele, a depressividade seria um movimento presente nas mais diversas formas de estados depressivos, mas de forma diferenciada. "A depressividade que se manifesta nos estados de distimia triste anormal é, fenomenologicamente, distinta em cada caso, e ainda mais diferente da depressividade melancólica" (Tellenbach, 1961/1999, p. 201).

As principais ideias que circundam a depressividade podem ser sutilmente percebidas na obra de Tellenbach (1969/1999, 1961/1999, 1976), porém ele não a alcança, uma vez que seus estudos tomam como foco o núcleo de modificação da subjetividade do melancólico e não se aprofundam sobre os modos existenciais que compõem o vivido depressivo e que se entrelaçam com a experiência de depressividade.

Desenvolver e aprofundar a temática da depressividade, à qual Tatossian $(1975,1977,1979 / 2006,1980)$ se refere no conjunto de sua obra, só foi possível mediante um constante diálogo manifestado em seus escritos com aqueles de Eugène Minkowski (1933/1995), Ludwig 
Binswanger (1960/2005) e Hubert Tellenbach (1961/1976, 1969/1999, 1976). Assim, abriram-se caminhos para Tatossian desenvolver uma proposta de psicopatologia fenomenológica mais amadurecida na contemporaneidade. Afirmar que a ideia de depressividade já se fazia presente, mesmo que indiretamente, nos textos de Minkowski, Binswanger e Tellenbach é uma observação que necessitaria de maiores investigações e aprofundamentos teóricos que escapam ao objetivo deste trabalho. Contudo, são pensadores com os quais Tatossian dialoga, hora se aproximando, ora se afastando ou mesmo criticando, mas que se fazem presentes na vastidão de seus escritos e que contribuíram sobremaneira para embasar e fundamentar a proposta que vislumbrava. Minkowski, Binswanger e Tellenbach não ignoraram o tema da depressividade em suas obras, mas não tinham os meios necessários em seus respectivos períodos históricos para alcançá-la. O seu desenvolvimento só foi possível tardiamente com os estudos de Tatossian, quando todo o cenário da tradição da psicopatologia fenomenológica já estava alicerçado e semeado pelas ideias fecundas dos autores que o precederam.

\section{A EXPERIÊNCIA DE DEPRESSIVIDADE NO PENSAMENTO DE ARTHUR TATOSSIAN}

O vocábulo depressividade, como tal, é utilizado pela primeira vez por Arthur Tatossian, em um artigo intitulado Le sens de la dépression, publicado em 1977. Nesse escrito, Tatossian (1977) se questiona sobre o que é a depressão, qual a sua origem e seus desdobramentos. Para tanto, utiliza como ponto de partida aquilo que ele chama de fatores depressógenos, os quais, quando se mostram às pessoas, revelam "a depressão como um estado atual e efetivo da depressividade que permite a aparição em certas pessoas e determinadas situações" (Tatossian, 1977, p. 34).

Essa concepção, como assinala Tatossian (1977), de atribuir à depressividade um traço permanente da personalidade do sujeito, é tentadora, porém arriscada. Ele ressalta que a depressão pode se manifestar em qualquer tipo de estrutura, e que a reação ou a vulnerabilidade dos indivíduos em assumirem um quadro depressivo relaciona-se com uma ação conjugada de certos tipos de personalidade, em determinados períodos da vida e em certas situações. O mais importante, entretanto, nas circunstâncias que antecedem a depressão, é o problema, normalmente esquivado, da mudança. A pessoa é convidada a manifestar outras formas de colocar-se no mundo, mas se revela incapaz de efetivar qualquer alteração (Tatossian, 1977).

Tatossian (1977) expressa que a falta de uma reação à mudança, no sujeito deprimido, está relacionada com a ausência de uma confiança fundamental, que não se exibe como um sentimento psicológico, mas como algo de ordem mais primitiva, manifesto como uma comunicação vital entre o homem e o mundo.

A ausência dessa confiança fundamental é seguramente uma das fontes da depressividade mas não a única, pois em todos os estágios da vida ela precisa ser reativada e confirmada, durante a fase edipiana, a adolescência, ao período pós-parto e as sucessivas renúncias impostas após a meia-idade. (Tatossian, 1977, p. 34, tradução livre)
Partindo dessa perspectiva, entendemos que a depressividade é um modo de ser global do indivíduo, não atrelada diretamente a fatores determinantes específicos. A depressividade é algo próprio da depressão e facilita a manifestação desta em certos sujeitos. Ela estaria em sua base constitutiva, fazendo-se presente em todos os depressivos como condição de possibilidade.

O caminho trilhado, por Tatossian (1977), para a compreensão da depressividade se aproxima daquele estudado por Tellenbach (1961/1976, 1969/1999, 1976) acerca das depressões endógenas, no que se refere ao movimento originário e espontâneo da noção de endon. Este comporta dados da experiência pré-flexiva, por ser da ordem do fenômeno, encontrando-se em um terceiro campo situado na interseção entre soma e psique. Os estudos de Tellenbach (1969/1999) foram pautados em sua experiência clínica de atendimento a pacientes depressivos, dando espaço para a emergência do fenômeno sem encarcerá-lo por meio dos conceitos da atitude natural. É o encontro com os aspectos transcendentais da experiência, sem deixar de lado os seus dados concretos, postura essa que se evidencia no desenvolvimento da noção de typus melancholicus ${ }^{1}$ e que atravessa a compreensão da depressividade.

Como ressaltam Leite e Moreira (2009), a contribuição de Tellenbach e Tatossian para a psicopatologia fenomenológica volta-se para uma "concepção de homem que transcende o caráter biológico" (p. 55) e suas formas de adoecimento não podem ser inferidas por meio de seus sintomas, pois compreendem um movimento próprio do viver humano sempre em fluxo.

Assim como a noção de endon, já trabalhada por Tellenbach (1961/1976, 1969/1999), a depressividade não é um conceito fechado em si mesmo, com origem na qual podemos racionalizar e fazer elaborações sumariamente teóricas. Embora um aparato teórico bem desenvolvido nos aproxime de sua compreensão.

1 Conceito desenvolvido por Hubert Tellenbach ao atender 119 pacientes na clínica psiquiátrica da universidade de Heidelberg. 
Na obra Fenomenologia das Psicoses, Tatossian (1979/2006) discute e aprofunda o tema da depressividade, mas com suporte na noção de experiência. Segundo ele (1979/2006), “a experiência da depressividade como fenômeno a apreende enquanto modo de ser global do depressivo em seu encontro consigo mesmo, com o mundo e com outrem" (p. 113). Possui um dado de especificidade ao só poder ser pensada como uma experiência précientífica do Lebenswelt - mundo vivido - a partir de um empirismo apriorístico, uma vez que "o objetivo não é, pois, construir teorias a partir da experiência, mas realçar um novo modelo de experiência, se necessário, para intermediar teorias" (Tatossian, 1979/2006, p. 114). Não é pensar a depressividade como uma forma ou um tipo de manifestação depressiva, dentro de um modelo rígido, mas como algo ocorrente na intersecção de um conhecimento $a$ priori constituído no percurso da psicopatologia e de uma compreensão fenomenológica da própria experiência.

A depressividade nos remete a uma noção de experiência pré-científica que resgata uma fenomenologia da atitude natural e que não se interessa pelas realidades materiais objetivas, mas por suas condições de possibilidade. É uma experiência própria do Lebenswelt - mundo da vida ou mundo vivido - que retoma o caráter originário e préreflexivo da experiência fenomenológica sem excluir seus dados empíricos em uma relação dialética. Não se trata de construir teorias por meio da experiência, mas é um novo modelo que visa a intermediar teorias, e a depressividade se mostra nesse sentido (Bloc, 2012; Tatossian, 1979/2006; Tatossian \& Moreira, 2012).

O conceito de Lebenswelt é oriundo do pensamento de Husserl, especialmente em sua última fase, e foi retomado por Merleau-Ponty como fio condutor de sua fenomenologia ambígua (Moreira, 2012). Refere-se a um mundo que já está posto, antes mesmo de ser pensado, e que não comporta nenhum traço de dualidade. "O Lebenswelt é simultaneamente sujeito e objeto, se dá no mundo, no entrelaçamento entre universal e singular, no quiasma" (Moreira, 2012, p. 19). Por se encontrar nessa interseção, a experiência do Lebenswelt não comporta uma dualidade entre interior e exterior, individual e social, mas se constitui no entrelaçamento ambíguo de tais manifestações, como um empirismo apriórico, e é nesse sentido que compreendemos a depressividade.

A depressividade não é um modelo estático, uma forma do vivido depressivo, mas sim uma compreensão que podemos situar na interseção do empirismo da experiência que se mostra, sobretudo, na clínica, e a teoria, um a priori construído no caminho de compreensão da psicopatologia. (Bloc, 2012, p. 193)

A proposta de Tatossian (1979/2006) e sua preocupação em construir uma psicopatologia fenomenológica que priorizasse a experiência, no sentido do Lebenswelt, recusa a ideia de uma clínica (seja ela psiquiátrica, psicoterapêutica, ou clinica psicológica ampliada) pautada na aplicação técnica de conhecimentos filosóficos. Pelo contrário, procura desenvolver uma "psicopatologia da clínica e para a clínica" (Moreira, 2012, p. 210) se aproximando de uma clínica do Lebenswelt, na qual a compreensão das psicopatologias se dá por meio do entrelaçamento da experiência vivida e daquilo que sabemos anteriormente a ela.

Segundo a psicopatologia tradicional, podemos ter a experiência de que alguém é depressivo, mas nunca do que é a depressividade, pois, como ressalta Tatossian (1979/2006, 1980), a depressividade é formada como uma hipótese generalizante oriunda de experiências diversas, que resulta de uma interpretação e se confronta com as experiências ulteriores. Enquanto isso, a definição da experiência de que alguém é depressivo pode ser alcançada por meio de comportamentos gestuais, mímicos e conteúdos e formas de falar, que compõem dados empíricos (Bloc, 2012; Tatossian, 1979/2006, 1980).

Pensar sobre a experiência de depressividade é opor-se a uma lógica de pensamento puramente racional e objetivo, que visa a reduzir sua compreensão para acessar apenas aquilo que pode ser manipulado tecnicamente. Como certifica Tatossian (1979/2006, p. 114), "uma tal concepção é eminentemente apropriada para aumentar nosso domínio técnico sobre o que nos rodeia", mas não para nos auxiliar na compreensão daquilo que é a depressividade.

Tatossian (1979/2006) retoma uma perspectiva que compreenda os modos existenciais psicopatológicos por meio do movimento próprio da experiência vivida, sem desconsiderar o a priori do fenômeno em questão. Não se trata, então, de compreender apenas a depressão e o conteúdo material que a encerra, mas a depressividade, como aquilo que engloba o vivido depressivo sem, contudo, esgotá-lo em si mesmo. É o entrelaçamento ambíguo e em constante transformação que compõe o encontro do clínico com o paciente, circundando a depressividade. Esse movimento da experiência já se fazia presente, de um modo embrionário, desde o início da tradição fenomenológica em psicopatologia, sendo radicalizado por Tatossian ao pensar uma compreensão ambígua dos quadros psicopatológicos via experiência do Lebenswelt.

Para se compreender a depressividade como fenômeno não se deve partir de uma perspectiva puramente teórica. $\mathrm{O}$ domínio instrumental sobre dado fenômeno de adoecimento pode ser ampliado, estendido e diversificado, mas isso não significa que teremos uma compreensão mais aprofundada. $\mathrm{Na}$ experiência fenomenológica da depressão, todo o seu aparato conceitual é dado, mas a depressividade o é sempre com um depressivo e em sua experiência (Tatossian, 1980). Partindo de um exemplo concebido por Blankenburg, Tatossian (1979/2006) entende que,

Não podemos afirmar que a sra. X.. é depressiva, se não soubermos de antemão o que é a depressividade. Mas não 
saberíamos o que é a depressividade se não tivéssemos tido dela a experiência no curso de nossa vida sobre nós ou sobre outrem. (p. 114)

Dessa feita, podemos observar que a depressividade aparece no pensamento de Arthur Tatossian (1979/2006) como base constitutiva do que é a depressão, concebendo esta como um movimento que se delineia com base na experiência e não como um traço conceitual delimitado que dirá sobre a personalidade do sujeito. Tê-la experienciado no decorrer da vida não significa dizer que ela se encontra categoricamente fixada, pois é algo que sempre está por vir e que se manifesta como uma possibilidade na experiência, comportando sempre um movimento em fluxo.

Podemos ler, investigar e apreender em textos e estudos fenomenológicos, dentro de uma atitude natural, o que eles expõem e explicitam teoricamente sobre cada fenômeno, inclusive com passagens que ilustram as possibilidades de aplicação clínica sobre cada caso particular. Não poderíamos, entretanto, falar sobre a depressividade utilizando apenas esta lente disssociada da experiência de quem a vivencia. De acordo com Tatossian (1980/2012),

Estas passagens teóricas não visam jamais predizer a partir de um caso dado o que são os outros, quer dizer, fornecer com antecedência as respostas aos problemas não ainda postos na experiência, mas bem antes aprender uma maneira de questionar o homem são ou doente e a conquistar a experiência fenomenológica. Cada doente impondo que a teoria seja refeita sob novos custos, a prática aparecendo sempre como teoria... A relação entre teoria e prática, ou antes, entre os dois aspectos que têm lugar aqui é, então, de implicação e não de aplicação (p. 98).

A depressividade não pode ser definida a partir da experiência, ou seja, de uma forma exteriorizada e objetiva, em que nos distanciamos e passamos a racionalizar a seu respeito, mas sobre e na experiência, pois o a priori fenomenológico se manifesta nos espaços familiares de possibilidades desta experiência, não sendo dela independente (Tatossian, 1979/2006).

No encontro com um depressivo temos, pois, a experiência de que ele é depressivo, mas também do que é a depressividade, nossa experiência se faz por sua vez com ele e com a depressividade, mesmo se esta é dada não como tema, mas como co-experiência. Esta co-experiência marginal não é aquela de um objeto em face de nós, mas de um estado que engloba o que é visado e aquilo que o visa. (Tatossian, 1979/2006, p. 115)

É um modelo de compreensão do adoecimento psicopatológico que não se apresenta sempre com esteio em um pensamento reflexivo e externalizado, mas como uma "co-experiência", em que temos a depressão e também a experiência do sujeito depressivo. É uma constante relação entre passividade e atividade, receptividade e espontaneidade, em que o "movimento próprio de nós mesmos, incorporando o movimento essencial do outro por um "pensamento receptivo"" (Tatossian, 1979/2006, p. 115) mantém o objeto da experiência que se constrói e é construído nessa relação paradoxal que incorpora.

A depressividade, então, consegue expressar bastante acerca da depressão, mas sem esgotá-la em si mesma, pois é construída continuamente mediante a singularidade da experiência de cada sujeito e comporta o movimento próprio de sua relação com o mundo. Apesar de termos discutido o vivido depressivo através das categorias fenomenológicas do tempo, corpo, espaço e da relação com o Outro e com a morte², é importante ressaltarmos que esses fenômenos não sinalizam uma redução do vivido depressivo em estilos enrijecidos ou homogêneos. Eles tornam a depressão possível e configuram os seus modos de ser enquanto tal, não correspondendo a sintomas fechados. Como assinala Bloc (2012), as categorias fenomenológicas não têm a capacidade de esgotar ou definir a depressão, mas compreender a depressividade como algo que se posiciona na interseção do que sabemos acerca do vivido depressivo e de seus modos de funcionamento e o que apreendemos por meio da experiência vivida pelo sujeito.

Compreender a depressividade por meio de um tempo estagnado, de um corpo pesado, de um espaço vazio e sem horizonte e de uma relação que perde a comunicação vital com o outro nos aponta o caminho para o modo de funcionamento global do deprimido e de como ele vivencia este estado (Bloc, 2012), mas o movimento da experiência, próprio do Lebenswelt de cada sujeito, e que comporta o traço de uma co-experiência marginal atrelada à depressividade só é alcançado através do contato com o paciente em uma perspectiva clínica que o priorize.

Podemos discutir, teorizar e questionar a experiência de depressividade, buscando compreender os seus modos de aparecimento e aquilo o que a possibilita enquanto tal, mas não é possível de fato alcançá-la por meio dos livros, pois estaríamos deixando de lado aquilo o que a constitui em um movimento contínuo e próprio da fluidez da existência humana, ou seja, a experiência fenomenológica unicamente atingida através do contato com o paciente.

Pensar a depressividade por meio de uma psicopatologia que se faça na clínica e para a clínica, sustentada na experiência do Lebenswelt que se dá nesse entrelaçamento (Moreira, 2012), auxilia-nos a entender como Tatossian $(1975,1977,1979 / 2006,1980)$ percebia e compreendia os fenômenos psicopatológicos bem como a sua contribuição para o desenvolvimento da psicopatologia fenomenológica na contemporaneidade. Seu compromisso central com a experiência clínica sustenta um constante diálogo com Minkowski, Binswanger (1960/2005) e Tellenbach (1961/1976, 1969/1999, 1976), os quais contribuíram para o desenvolvimento da experiência de depressividade.

2 A ver item 2.3 


\section{CONSIDERAÇÕES FINAIS}

A princípio, seria simples entender a experiência de depressividade como um tipo de depressão ou até como sinônimos, porém não é o caso. Existe uma distinção nítida e evidente entre depressão e depressividade. A compreensão da experiência de depressividade se dá pela via de um pensamento fenomenológico ambíguo, que caminha na interseção daquilo que sabemos sobre o vivido depressivo e de seus mundos constituintes e daquilo que é de ordem experiencial, que está em um constante processo de transformação e movimento próprios da experiência fenomenológica do Lebenswelt de cada sujeito.

Nesse sentido, a experiência de depressividade não seria apenas um desdobramento da depressão, mas corresponderia a uma passagem possibilitada por uma mudança de visão, possibilitada pela lente fenomenológica ambígua. Só podemos entender a experiência de depressividade se anteriormente a ela soubermos o que é a depressão e, da mesma forma, só podemos pensar a depressão porque nela já está imbricada a depressividade. Elas se compõem, então, em uma relação de mútua constituição e entrelaçamento constantes.

Essa distinção é o cerne central da tradição fenomenológica em psicopatologia, que visava a uma ruptura das noções dicotômicas e classificatórias dos transtornos mentais, indo além de uma abrangência linear, causal e centrada nos dados sintomatológicos. Compreender a depressão como fenômeno é uma tentativa presente nos quatro autores que, neste artigo, representam a tradição da psicopatologia fenomenológica, a saber, Minkowski, Binswanger, Tellenbach e, aprofundando o tema da depressividade, Tatossian, mas cada qual trilhando um percurso próprio e dando os passos necessários para a emergência de uma posterior compreensão desta experiência.

A proposta de Tatossian gira em torno da ideia de uma psicopatologia fenomenológica que compreende os modos existenciais adoecidos por meio do fluxo da experiência do paciente. Ele se propunha a resgatar o movimento próprio dos fenômenos psicopatológicos, compreendendo-os para além de seu enrijecimento sintomático, de fato, delineandoos como fenômenos constitutivos e constituintes da experiência de cada sujeito. Assim, não se trata de estudar a depressão, mas o entrelaçamento ambíguo e em constante transformação do encontro do clínico com o paciente. Esse movimento, que é descrito na experiência de depressividade, já se fazia presente desde o início da tradição fenomenológica em psicopatologia, mas de forma embrionária, sendo radicalizado por Tatossian ao desenvolver sua compreensão ambígua dos quadros psicopatológicos.

Por estar estritamente vinculada à noção de experiência fenomenológica, não podemos alcançar a globalidade da experiência de depressividade por meio de elaborações e estudos teóricos e nos isolarmos, como ponderava Tatossian (1979/2006, p. 29), como "o filósofo transcendental em sua torre de marfim". Compreender a depressividade é considerar o aparato teórico e, simultaneamente, retornar à experiência imediata e ao encontro com o paciente, aos quais se dá no espaço da clínica. Caso contrário, estaríamos teorizando sobre um conceito e deixando de lado todos os dados que também constituem a experiência do paciente.

Concluímos que Arthur Tatossian contribuiu sobremaneira para a construção da noção de depressividade, como parte de uma psicopatologia fenomenológica contemporânea mais amadurecida, ao dialogar com as ideias dos grandes marcos da psicopatologia fenomenológica e trilhar um caminho de compreensão do adoecimento mental que se faça na clínica e para a clínica. Ao compreendermos a depressividade no entrelaçamento daquilo que sabemos sobre ela e de uma experiência que está sempre por vir, nunca encerrada em si mesma, seguimos o caminho para pensarmos uma psicopatologia fenomenológica ambígua, construída no movimento único de uma experiência própria do Lebenswelt de cada sujeito. Essa ideia pode vir a enriquecer as pesquisas sobre o fenômeno da depressão, buscando contribuir para o tratamento e prevenção dessa doença que se tornou a epidemia do mundo contemporâneo.

\section{REFERÊNCIAS}

Abreu e Silva, N. N. (2004). A atualidade da obra de Eugène Minkowski (1985 - 1972). Boletim Academia Paulista de Psicologia, 24(2), 50-62.

Ambrosini, A., Stanghellini, G., \& Langer, Á. I. (2011). El Typus melancholicus de Tellenbach en la actualidad: Una revisión sobre la personalidad premórbida vulnerable a la melancolía. Actas Españolas de Psiquiatría, 39(5), 302-311.

Binswanger, L. (2005) Mélancolie et manie: Etudes phénoménologiques. Paris: Presses Universitaires de France. (Publicado originalmente em 1960)

Bloc, L. (2012). Introdução à psicopatologia fenomenológica de Arthur Tatossian (Dissertação de mestrado não publicada). Instituto de Psicologia, Universidade de Fortaleza, Fortaleza, Brasil.
Costa, V. E. S. M., \& Medeiros, M. (2009). O tempo vivido na perspectiva fenomenológica de Eugène Minkoski. Psicologia em Estudo, 14(2), 375-383.

Fédida, P. (2009). Dos benefícios da depressão. São Paulo: Escuta. Leite, M. E., \& Moreira, V. (2009). A contribuição de Tellenbach e Tatossian para uma compreensão fenomenológica da depressão. Arquivos Brasileiros de Psicologia, 61(3), p. 46-56.

Minkowski, E. (1995). Le temps vécu. Paris: Presses Universitaires de France. (Trabalho original publicado em 1933)

Moreira, V. (2011) A contribuição de Jaspers, Binswanger, Boss e Tatossian para a psicopatologia fenomenológica. Revista da Abordagem Gestáltica, 17(2), 178-190.

Moreira, V. (2012). A contribuição de Jaspers, Binswanger, Boss e Tatossian para a psicopatologia fenomenológica. In 
A. Tatossian \& V. Moreira (Orgs.), Clínica do Lebenswelt: Psicoterapia e psicopatologia fenomenológica (pp. 189-217). São Paulo: Escuta.

Tatossian, A. (1975). Phénoménologie de la Depression. Psychiatries, 21, 77-85.

Tatossian, A. (1977). Le sens de la dépression. Méditerranée Médical, 5, 146, 33 - 36.

Tatossian, A. (2006). A fenomenologia das psicoses. São Paulo: Escuta. (Original publicado em 1979)

Tatossian, A. (1980). Théorie et pratique en psychiatrie: Symptôme et phénomène, un point de vue phénoménologique. Acv. Psychiatr., 10, 59-63.

Tatossian, A. (2012). Teoria e Prática em psiquiatria: Sintoma e fenômeno, um ponto de vista fenomenológico. In A. Tatossian \& V. Moreira (Orgs.), Clínica do Lebenswelt: Psicoterapia e psicopatologia fenomenológica (pp. 91-100). São Paulo: Escuta. (Original publicado em 1980)

Tatossian, A., \& Moreira, V. (2012). Clínica do Lebenswelt: Psicoterapia e psicopatologia fenomenológica. São Paulo: Editora Escuta.
Tellenbach, H. (1999). A endogeneidade como origem da melancolia e do tipo melancólico. Revista Latinoamericana de Psicopatologia Fundamental, 2(4), 164-175. (Trabalho original publicado em 1969)

Tellenbach, H. (1976). Melancolía. Madrid: Ediciones Morata. (Trabalho original publicado em 1961)

Recebido em: 10/07/2015

Aceito em: 27/03/2017 